\title{
Effects of Beverage Ingredients on Salivary Fluid Secretion with an ex Vivo Submandibular Gland Perfusion System: Tannic Acid as a Key Component for the Inhibition of Saliva Secretion
}

\author{
Atsushi Imamura, Tetsuji Nakamoto*, Taro Mukaibo, Takashi Munemasa, Yusuke Kondo, \\ Manami Kidokoro, Chihiro Masaki, Ryuji Hosokawa \\ Department of Oral Reconstruction and Rehabilitation, Kyushu Dental University, Kitakyushu, Japan \\ Email: nakamoto@kyu-dent.ac.jp
}

Received 23 December 2014; accepted 15 January 2015; published 22 January 2015

Copyright (C) 2015 by authors and Scientific Research Publishing Inc.

This work is licensed under the Creative Commons Attribution International License (CC BY).

http://creativecommons.org/licenses/by/4.0/

(c) (i) Open Access

\begin{abstract}
Tannic acid (TA) and TA containing beverage have been proved to inhibit $\mathrm{Ca}^{2+}$-activated $\mathrm{Cl}^{-}$channel located apical membrane of the secretory cells. However, their effect on salivary fluid secretion is not well investigated. We used mouse ex vivo submandibular gland perfusion technique to identify the general effect of TA and related beverage samples on muscarinic agonist carbachol induced fluid secretion. Green tea inhibited fluid secretion by $64 \%$ from the control, where oolong tea was by $53 \%$, and red wine by $43 \%$ which was linked with their TA concentration. On the other hand, though TA was contained at $4.7 \mu \mathrm{M}$ in white wine sample and $33 \mu \mathrm{M}$ in coffee extract, no adverse effect was observed. In addition, coffee induced salivation in the absence of carbachol. TA had a negative effect on fluid secretion with a concentration dependent manner. The effects of TA on carbachol induced calcium increase showed identical as fluid secretion, which was initially no effect, and then gradually decreased over the time. These results demonstrate that TA directly inhibits the salivary fluid secretion and it affects not only $\mathrm{Ca}^{2+}$-activated $\mathrm{Cl}^{-}$channel but also intracellular $\mathrm{Ca}^{2+}$ increasing mechanisms.
\end{abstract}

\section{Keywords}

Saliva Secretion, Red Wine, Tannic Acid, $\mathrm{Ca}^{2+}$ Activated $\mathrm{Cl}^{-}$Channel

\footnotetext{
"Corresponding author.
}

How to cite this paper: Imamura, A., et al. (2015) Effects of Beverage Ingredients on Salivary Fluid Secretion with an ex Vivo Submandibular Gland Perfusion System: Tannic Acid as a Key Component for the Inhibition of Saliva Secretion. Open Journal of Stomatology, 5, 12-18. http://dx.doi.org/10.4236/ojst.2015.51003 


\section{Introduction}

Saliva is one of the most important components in the oral cavity, which helps taste sensation, speech, mastication, swallowing and protects oral mucosa and teeth [1] [2]. It is originally made from the blood, the most of it in three major salivary glands, parotid, submandibular and sublingual glands. Salivary glands consists two components: one is acinar cells where isotonic fluid is made; and the other is ductal cells where absorb most of $\mathrm{NaCl}$, and add $\mathrm{K}^{+}$and $\mathrm{HCO}_{3}^{-}$in original saliva, and final saliva become hypotonic [3]. Hypo-tonicity in final saliva is very important for the taste sensation because food ingredients diffuse to reach the taste bud for the digestion of the food [1]. On the other hand, salivary glands are very sensitive tissues, since lots of people with general medications tend to have dry mouth. Transcellular anion transport especially in salivary acinar cells has a key role for regulating the fluid (water) secretion; these are mainly composed of two anion inlet transporters in basolateral membrane and outlet in apical membrane. The former one is mainly composed of $\mathrm{Na}^{+}-\mathrm{K}^{+}-2 \mathrm{Cl}^{-}$cotransport [4] and partially of anion exchangers working simultaneously $\mathrm{Na}^{+} / \mathrm{H}^{+}$exchangers [5]. The latter component was accomplished by intracellular $\mathrm{Ca}^{2+}$ activated anion channels located apical membrane of the salivary acinar cells which was identified in 2008 [6]-[8]. After molecular identification of this anion channel, the pharmacological and physiological properties of this channel have been analyzed, and TA has been proposed as one of the most potent inhibitors [9]-[14]. TA and TA containing green tea and red wine are reported to inhibit $\mathrm{Ca}^{2+}$ activated anion conductance [12]. However, the direct effect on salivary fluid secretion is not well investigated. In the present study, we used a biological sensor — ex vivo mouse submandibular gland perfusion technique- to identify the effect of the TA including beverage ingredients on the glandular function.

\section{Materials and Methods}

\subsection{Preparation of the Biological Glandular Sensor}

All experiments were approved by the Animal Committee of Kyushu Dental University. C57BL/6J mice, 8 - 10 weeks of age were purchased from Kyushu Animal Laboratory. The mice were habituated and the experiments were performed when the mice were 8 - 12 weeks of age. The mice were exposed to a 12-h light/dark cycle and fed ad libitum. An ex vivo vascular perfusion technique was used for glandular fluid secretion analysis. The surgical procedure used has been described previously [14]. In brief, mouse were anesthetized with chloral hydrate $(400 \mathrm{mg} / \mathrm{kg})$, then dissected the blood vessels around the submandibular gland under a dissecting microscope (Olympus SZX7). The main artery directly going into the gland was dissected, and then blanches was tied with silk sutures, and then the glands were transferred to perfusion chamber. Then the 31 gauge blunt end needle was cannulated into the main artery. Physiological saline solution, which contains $120 \mathrm{mM} \mathrm{NaCl}, 4.3 \mathrm{mM} \mathrm{KCl}, 25$ $\mathrm{mM} \mathrm{NaHCO}_{3}, 1.0 \mathrm{mM} \mathrm{MgCl}_{2}, 1.0 \mathrm{mM} \mathrm{CaCl}_{2}, 5 \mathrm{mM}$ glucose, $10 \mathrm{mM}$ HEPES (equilibrated with $95 \% \mathrm{O}_{2}$ and $5 \%$ $\mathrm{CO}_{2}$ ) was perfused at a rate of $1 \mathrm{ml} /$ minute. Glands were kept at 37 degree with originally made water jacket heating system. The diagrammatic illustration of ex vivo biological saliva collection system is shown in Figure 1. Salivation was induced with cholinergic agonist carbachol (CCh) for 10 minutes at $0.3 \mu \mathrm{M}$, which we set as control. The effects of beverage ingredients were analyzed by perfusing the gland with from 5 minutes prior to CCh stimulation. Secreted saliva was collected in the glass capillary tube and then the flow rate and total amount was calculated. Flow rates and total amount with and without target samples were compared.

\subsection{Intracellular $\mathrm{Ca}^{2+}$ Signaling Analysis}

Clumpy cell preparation was performed for the analysis of cellular secretory signaling. Dissected glands were transferred into Krebs-Henseleit Ringer solution, which contains $103 \mathrm{mM} \mathrm{NaCl}, 4.7 \mathrm{mM} \mathrm{KCl}, 25 \mathrm{mM} \mathrm{NaHCO}$, $2.8 \mathrm{mM}$ glucose, $12.5 \mathrm{mM}$ HEPES, $1.2 \mathrm{mM} \mathrm{NaH}_{2} \mathrm{PO}_{4}, 4.9 \mathrm{mM}$ Na-pyruvate, $2.7 \mathrm{mM} \mathrm{Na}_{2}$-fumarate, $2.7 \mathrm{mM}$ Na-glutamate, $2.6 \mathrm{mM} \mathrm{CaCl}_{2}, 1.1 \mathrm{mM} \mathrm{MgCl} 2$ and bovine serum albumin $1 \mathrm{mg} / \mathrm{ml}$. Submandibular glands were then minced 100 times with scissors, and then put into the collagenase L (Nitta Gelatin, Osaka, Japan) containing buffer. The aliquot was then treated for 20 minutes under the continuous shaking (100 cycle/minute). The digested samples was then washed 3 times with $5 \mathrm{ml}$ of Ringer solution, and then intracellular calcium detecting fluorescent dye, acetoxymethyl ester Fura-2 (Fura-2 AM), was applied at $1 \mu \mathrm{M}$ for 10 minutes. The fluorescence was detected with excitation wave length 340 and $380 \mathrm{~nm}$ and the emission for $510 \mathrm{~nm}$ for both excitations with a fluorescence detecting system (Argus Aqua cosmos, Hamamatsu Photonics, Hamamatsu, Japan). Observation chamber was perfused at a rate of $1 \mathrm{ml} /$ minute at $37^{\circ} \mathrm{C}$. 


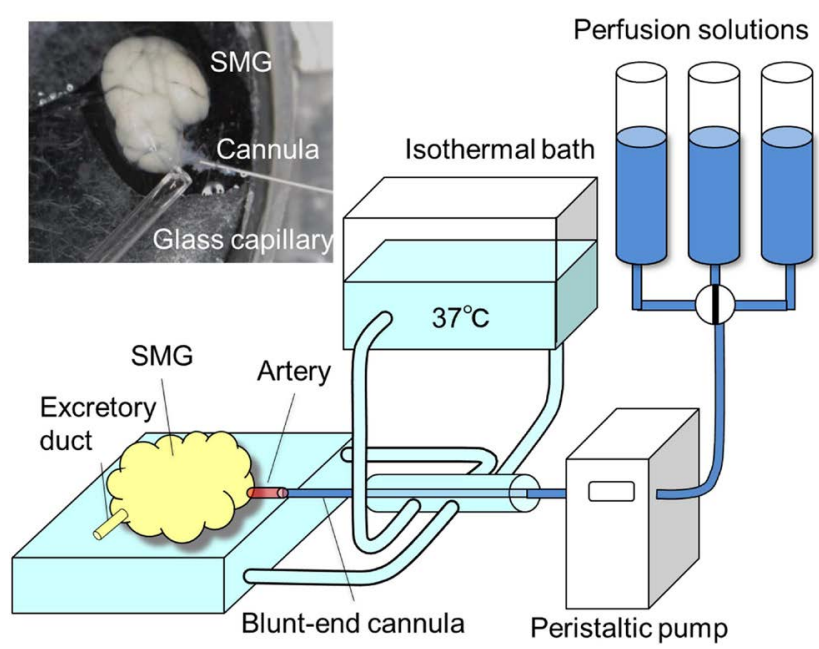

Figure 1. A pattern diagram and a picture of ex vivo submandibular gland perfusion analysis: submandibular gland was dissected out from the anesthetized mice and then perfused with physiological saline solution on water jacket heating stage at $37^{\circ} \mathrm{C}$. Perfusion solutions were switched to each test solution, and then their effect on muscarinic agonist carbachol induced fluid secretion was measured. Saliva samples were collected with glass capillary tube and the progression was marked to calculate flow rate.

\subsection{Preparation of Beverage Samples}

Green tea (Yamecha, Takeya Shouten, Kitakyushu, Fukuoka, Japan) oolong tea (Itoen, Tokyo, Japan) and coffee (Ueshima Coffee Co., Ltd., Sapporo, Japan) were prepared soaking the $2.5 \mathrm{~g}$ of tea leafs or grinded coffee into $30 \mathrm{ml}$ of boiling water for 10 minutes, the extracted samples were then filtrated then frozen until used. Red wine (Maison Belleroche Bordeaux Rouge, 2010, France) and white wine (Carlo Rossi, 2008, USA) were boiled until the volume became half to completely remove alcohol, and then filtrated as Numkang et al. reported [12]. For the functional analysis, prepared beverage samples were added into the physiological saline solutions at $1.2 \%$ for green tea, oolong tea and coffee, and $2 \%$ for red and white wine. The extracted and concentrated samples were then measured their TA concentration by Folin-Denis assay or official method of analysis which was performed by Japan Food Laboratories (Fukuoka, Japan).

\subsection{Chemicals}

Collagenase L was obtained from Nitta Gelatin (Osaka, Japan) and Fura-2 AM was from Dojindo (Kumamoto, Japan). Other chemicals were all from Sigma Japan (Tokyo, Japan).

\subsection{Statistical Analysis}

For the comparison of pairwise samples Student t-test was used, and ANOVA with Tukey post hoc test was used for multiple comparisons. P-value less than 0.05 was set as statistically significant.

\section{Results}

\subsection{Tea Compounds and Red Wine Extracts Inhibit Fluid Secretion in the Mouse ex Vivo Submandibular Gland Perfusion System}

The effects of tea and wine extracts on fluid secretion were summarized in Figure 2(a) and Figure 2(b). As it shows beverage component induced no salivation except coffee (Figure 2(b)). When stimulated with moderate concentration of muscarinic agonist carbachol, inhibition on fluid secretion was observed for green tea, oolong tea and red wine. The initial inhibition was small, but the effects become larger over time. On the other hand 
white wine and coffee failed to show any change when compared with the control. The accumulated salivas over 10 minute's stimulation were summarized in Figure 2(c). When the data was normalized to control (CCh 0.3 $\mu \mathrm{M}), 40 \%-65 \%$ inhibition was observed for green tea, oolong tea and red wine, where coffee and white wine had no effect.

\subsection{The Effect of Tannic Acid on Fluid Secretion in the Mouse Submandibular ex Vivo Gland}

Chloride transport is a key component for fluid secretion. We hypothesized that TA which affects to $\mathrm{Ca}^{2+}$ activated anion channel might be the possible reason for green tea, oolong tea and red wine inhibition. The effects of TA at several concentrations were summarized in Figure 3(a). Significant inhibitions on fluid secretion were observed for all concentrations tested. The dose response inhibition and TA concentrations for green tea, oolong tea and red wine were summarized in Figure 3(b).

Since the shape observed in Figure 2(a) looked identical as TA at 30 or $100 \mu \mathrm{M}$ we then analyzed TA concentration used in the present study. The TA concentration was measured for each solution, and the final concentration used was $47 \mu \mathrm{M}$ for green tea, $34 \mu \mathrm{M}$ for oolong tea and $56 \mu \mathrm{M}$ for red wine.

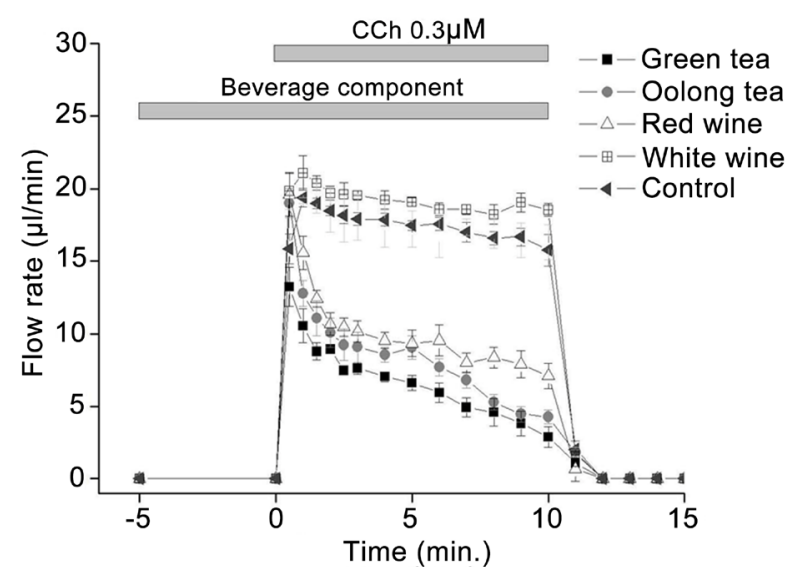

(a)

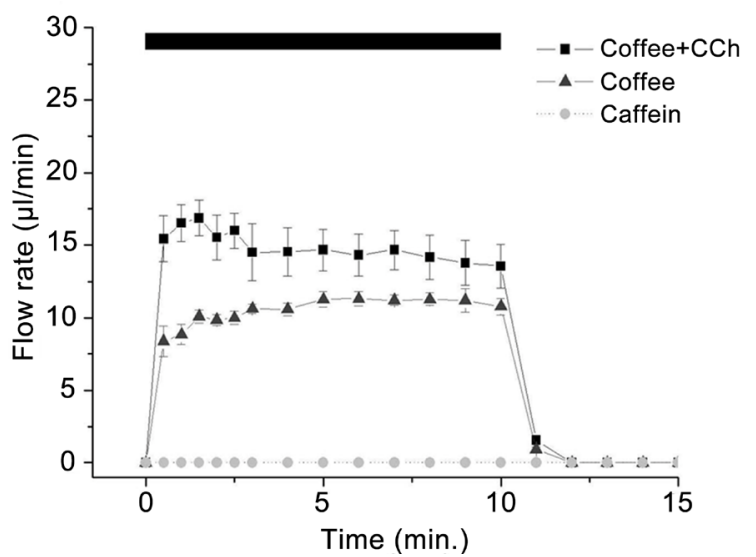

(b)

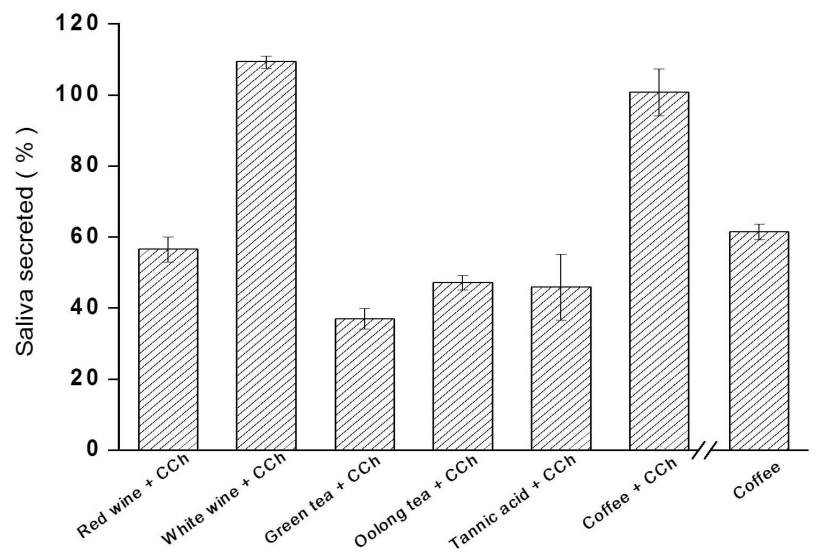

(c)

Figure 2. The effect of beverage component on fluid secretion. (a) The effect of green tea, oolong tea, red wine and white wine on muscarinic agonist carbachol (CCh) induced fluid secretion. The number of experiments are followings; green tea $(n=4)$, ooolong tea $(n=4)$, red wine $(n=5)$, white wine $(n=5)$ and CCh (control: $n=7)$; (b) The effect of coffee on CCh induced fluid secretion, and the effect of caffeine on fluid secretion. The number of experiments are followings; coffee $+\operatorname{CCh}(n=6)$, coffee $(n=4)$ and caffeine at $100 \mu M(n=3)$. Since coffee was potent to secrete, no prior perfusion was performed for Coffee + CCh; (c) The comparison of each beverage ingredients on fluid secretion. Total amount from 10 minutes collection period was compared from the control. The average amount of control secretion $(0.3 \mu \mathrm{M}$ CCh) was set as $100 \%$. The relative values were shown. 


\subsection{The Effect of Tannic Acid on Intracellular Calcium Signaling}

Carbachol induced fluid secretion from the mouse ex vivo submandibular gland was inhibited TA concentration dependent manner. We then analyzed TA on the muscarinic stimulation induced intracellular calcium increase. The effects were summarized in Figure 4 revealed that no significant effect on first 30 seconds suggesting TA had no negative effect on muscarinic receptors. However, the decrease become significant at the end suggesting calcium sustaining mechanisms are partially inhibited.

\section{Discussion}

Secretory function is crucial for the quality of life for the elderly, however little is known which beverage is suitable to preserve the function for fluid secretion in secretory glands. Their effect on cellular level has been reported, but in the present study we first report the effect of beverage compounds on fluid secretion with stable ex vivo mouse gland perfusion system. Of course the components might not directly go into the blood flow but minor salivary glands are spread in the oral cavity and glands are apically located in the gastrointestinal tract.

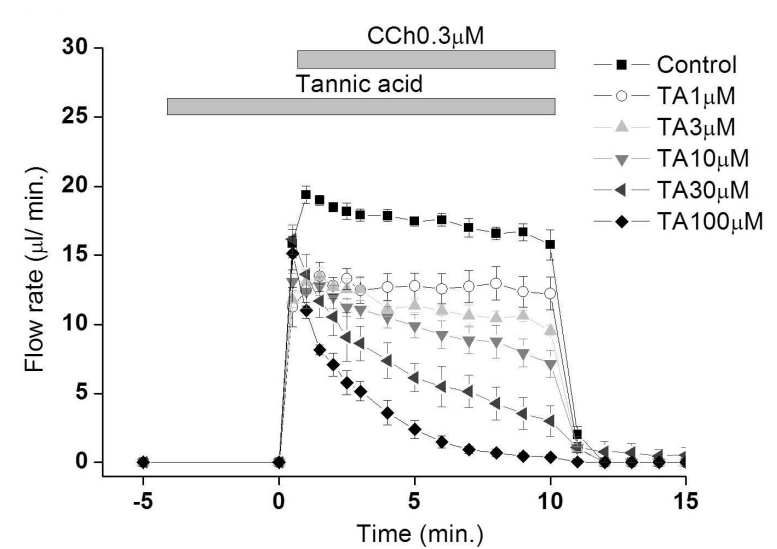

(a)

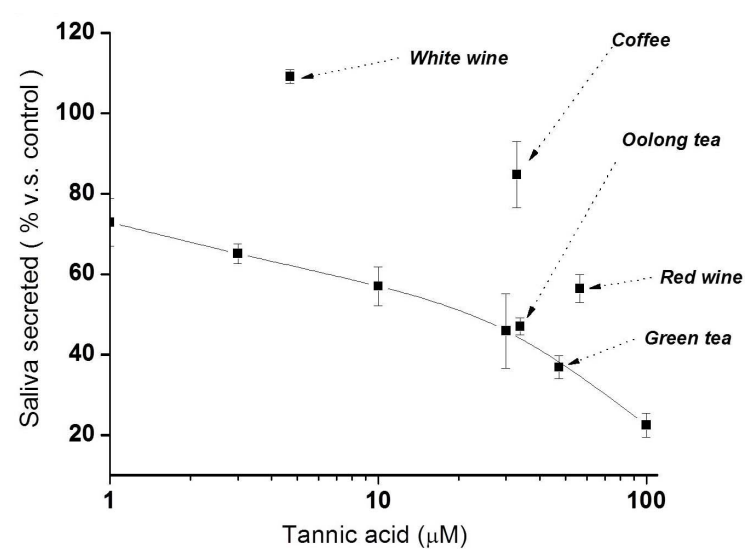

(b)

Figure 3. The effect of tannic acid (TA) on carbachol induced fluid secretion. (a) TA was applied from 5 minutes prior to 0.3 $\mu \mathrm{M}$ carbachol (CCh) stimulation. TA decreased fluid secretion in concentration dependent manner. The numbers of experiments are $n=4$ for all TA contained samples, and $n=7$ for the CCh control. The same samples were used as shown in Figure 2; (b) The dose response of TA on fluid secretion over 10 minutes collection time. The dots are showing TA concentration of each samples and fluid secretion from Figure 2(a) and Figure 2(b). The concentrations of TA were $47 \mu \mathrm{M}$ for green tea, $34 \mu \mathrm{M}$ for oolong tea, $33 \mu \mathrm{M}$ for coffee, $56 \mu \mathrm{M}$ for red wine and $4.7 \mu \mathrm{M}$ for white wine.

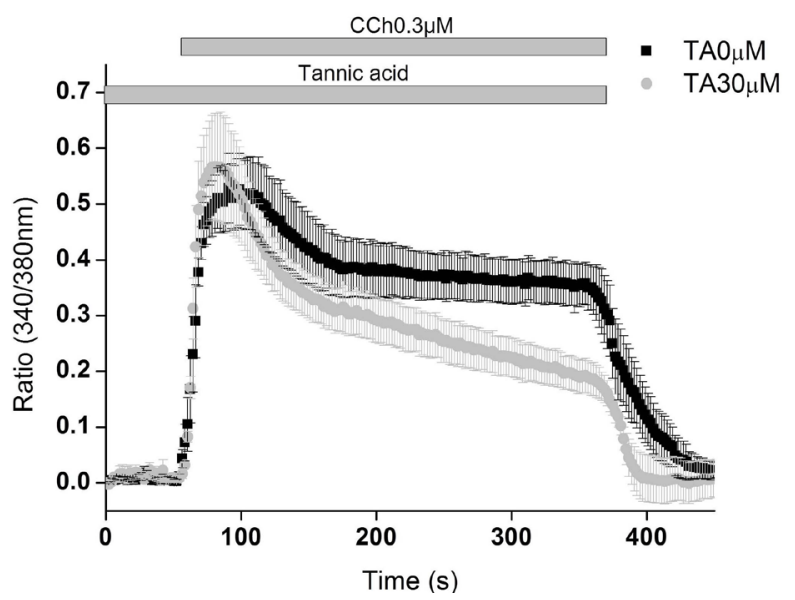

Figure 4. The effect of tannic acid (TA) on intracellular $\mathrm{Ca}^{2+}$ regulation: TA (30 $\left.\mu \mathrm{M}\right)$ had no effect on initial $\mathrm{Ca}^{2+}$ increase, however, it affects later phase. Significant decrease ( $46 \%)$ was observed at the end of CCh stimulation. The number of experiments (mice) were $\mathrm{n}=4$ for control (TA: $0 \mu \mathrm{M})$ and $\mathrm{n}=6$ for TA $(30 \mu \mathrm{M})$. 
Especially positive effects for green tea have been reported as it positive effects on chronic periodontitis, dental caries and oral cancer [15], which also have positive effect like colon cancer [16]. A survey research has been reported that three or more cups of coffee per day had a significant inverse association with upper aerodigestive tract cancer; where consumption of three or more cups of green tea per day had a significant positive association [17]. Though the clinical implication, the short term effect for their consumption.

The positive effects of red wine has been extensively studied, the consumption seemed to reduce cancer and appropriate taking has been proposed [18], and their anti-inflammatory effect on NF- $\kappa$ B has been proven in cellular level [19]. Though, its polyphenols have so many positive effects, red wine clearly decreased fluid secretion. On the other hand, though certain amount of TA $(4.7 \mu \mathrm{M})$, white wine had no effect on fluid secretion (Figure 3(b)).

We expected that coffee has negative effect on CCh induced fluid secretion since it contains TA. However, coffee itself was potent to secrete, and no effect on CCh induced fluid secretion. We first thought this was due to caffeine in coffee; however caffeine failed to induce salivation even when applied very high concentration (100 $\mu \mathrm{M})$ (Figure 2(b)). This is presumably due to the cholinomimetic compound in coffee which has muscarinic actions [20] [21] that might be strong enough to compensate negative effect from its TA (33 $\mu \mathrm{M})$.

The effect of TA on fluid secretion revealed almost no effect for first 30 seconds, but gradual decrease was seen during the observation period (Figure 3(a)), which was linked to intracellular calcium decrease (Figure 4). Suggesting that TA has no effect on muscarinic receptors but it affects not only on TMEM16A but also on intracellular calcium regulation like store operated calcium influx mechanisms as reported in human red blood cell [22]. A report said that xerostomia occurred in $45 \%$ of older adults, and a diagnosis of an oral symptom in only 4.5\% [23]. As previously mentioned, so many positive effects have been reported on teas and wines, but we might have to take into consideration short term effect especially elderly populations.

\section{Conclusion}

Tannic acid and beverages containing tannic acid such as green tea, oolong tea and red wine, inhibit salivary fluid secretion.

\section{Acknowledgements}

This work was supported by JSPS KAKENHI Grant Numbers 25293397, 25463011, 26861648.

\section{References}

[1] Pedersen, A.M., Bardow, A., Jensen, S.B. and Nauntofte, B. (2002) Saliva and Gastrointestinal Functions of Taste, Mastication, Swallowing and Digestion. Oral Diseases, 8, 117-129.

http://dx.doi.org/10.1034/j.1601-0825.2002.02851.x

[2] Carpenter, G.H. (2013) The Secretion, Components, and Properties of Saliva. Annual Review of Food Science and Technology, 4, 267-276. http://dx.doi.org/10.1146/annurev-food-030212-182700

[3] Melvin, J.E., Yule, D., Shuttleworth, T. and Begenisich, T. (2005) Regulation of Fluid and Electrolyte Secretion in Salivary Gland Acinar Cells. Annual Review of Physiology, 67, 445-469. http://dx.doi.org/10.1146/annurev.physiol.67.041703.084745

[4] Evans, R.L., Park, K., Turner, R.J., Watson, G.E., Nguyen, H.V., Dennett, M.R., et al. (2000) Severe Impairment of Salivation in $\mathrm{Na}^{+} / \mathrm{K}^{+} / 2 \mathrm{Cl}^{-}$Cotransporter (NKCC1)-Deficient Mice. The Journal of Biological Chemistry, 275, 2672026726.

[5] Park, K., Evans, R.L. and Melvin, J.E. (2000) Functional Roles of $\mathrm{Na}^{+} / \mathrm{H}^{+}$Exchanger Isoforms in Saliva Secretion. Journal of Korean Medical Science, 15, S5-S6. http://dx.doi.org/10.3346/jkms.2000.15.S.S5

[6] Yang, Y.D., Cho, H., Koo, J.Y., Tak, M.H., Cho, Y., Shim, W.S., et al. (2008) TMEM16A Confers Receptor-Activated Calcium-Dependent Chloride Conductance. Nature, 455, 1210-1215. http://dx.doi.org/10.1038/nature07313

[7] Caputo, A., Caci, E., Ferrera, L., Pedemonte, N., Barsanti, C., Sondo, E., et al. (2008) TMEM16A, a Membrane Protein Associated with Calcium-Dependent Chloride Channel Activity. Science, 322, 590-594. http://dx.doi.org/10.1126/science.1163518

[8] Schroeder, B.C., Cheng, T., Jan, Y.N. and Jan, L.Y. (2008) Expression Cloning of TMEM16A as a Calcium-Activated Chloride Channel Subunit. Cell, 134, 1019-1029. http://dx.doi.org/10.1016/j.cell.2008.09.003

[9] Huang, F., Rock, J.R., Harfe, B.D., Cheng, T., Huang, X., Jan, Y.N., et al. (2009) Studies on Expression and Function 
of the TMEM16A Calcium-Activated Chloride Channel. Proceedings of the National Academy of Sciences of the United States of America, 106, 21413-21418. http://dx.doi.org/10.1073/pnas.0911935106

[10] Huang, F., Zhang, H., Wu, M., Yang, H., Kudo, M., Peters, C.J., et al. (2012) Calcium-Activated Chloride Channel TMEM16A Modulates Mucin Secretion and Airway Smooth Muscle Contraction. Proceedings of the National Academy of Sciences of the United States of America, 109, 16354-16359. http://dx.doi.org/10.1073/pnas.1214596109

[11] Namkung, W., Phuan, P.W. and Verkman, A.S. (2011) TMEM16A Inhibitors Reveal TMEM16A as a Minor Component of Calcium-Activated Chloride Channel Conductance in Airway and Intestinal Epithelial Cells. Journal of Biological Chemistry, 286, 2365-2374. http://dx.doi.org/10.1074/jbc.M110.175109

[12] Namkung, W., Thiagarajah, J.R., Phuan, P.W. and Verkman, A.S. (2010) Inhibition of $\mathrm{Ca}^{2+}$-Activated $\mathrm{Cl}^{-} \mathrm{Channels} \mathrm{by}^{-}$ Gallotannins as a Possible Molecular Basis for Health Benefits of Red Wine and Green Tea. FASEB Journal, 24, 41784186. http://dx.doi.org/10.1096/fj.10-160648

[13] Namkung, W., Yao, Z., Finkbeiner, W.E. and Verkman, A.S. (2011) Small-Molecule Activators of TMEM16A, a Calcium-Activated Chloride Channel, Stimulate Epithelial Chloride Secretion and Intestinal Contraction. FASEB Journal, 25, 4048-4062. http://dx.doi.org/10.1096/fj.11-191627

[14] Romanenko, V.G., Catalan, M.A., Brown, D.A., Putzier, I., Hartzell, H.C., Marmorstein, A.D., et al. (2010) Tmem16A Encodes the $\mathrm{Ca}^{2+}$-Activated $\mathrm{Cl}^{-}$Channel in Mouse Submandibular Salivary Gland Acinar Cells. Journal of Biological Chemistry, 285, 12990-13001. http://dx.doi.org/10.1074/jbc.M109.068544

[15] Gaur, S. and Agnihotri, R. (2013) Green Tea: A Novel Functional Food for the Oral Health of Older Adults. Geriatrics \& Gerontology International, 14, 238-250.

[16] Sanchez-Tena, S., Vizan, P., Dudeja, P.K., Centelles, J.J. and Cascante, M. (2013) Green Tea Phenolics Inhibit Butyrate-Induced Differentiation of Colon Cancer Cells by Interacting with Monocarboxylate Transporter 1. Biochimica et Biophysica Acta, 1832, 2264-2270. http://dx.doi.org/10.1016/j.bbadis.2013.08.009

[17] Oze, I., Matsuo, K., Kawakita, D., Hosono, S., Ito, H., Watanabe, M., et al. (2013) Coffee and Green Tea Consumption Is Associated with Upper Aerodigestive Tract Cancer in Japan. International Journal of Cancer, 135, 391-400.

[18] Giacosa, A., Barale, R., Bavaresco, L., Gatenby, P., Gerbi, V., Janssens, J., et al. (2013) Cancer Prevention in Europe: The Mediterranean Diet as a Protective Choice. European Journal of Cancer Prevention: The Official Journal of the European Cancer Prevention Organization, 22, 90-95. http://dx.doi.org/10.1097/CEJ.0b013e328354d2d7

[19] Nunes, C., Ferreira, E., Freitas, V., Almeida, L., Barbosa, R.M. and Laranjinha, J. (2013) Intestinal Anti-Inflammatory Activity of Red Wine Extract: Unveiling the Mechanisms in Colonic Epithelial Cells. Food \& Function, 4, 373-383. http://dx.doi.org/10.1039/c2fo30233k

[20] Tse, S.Y. (1991) Coffee Contains Cholinomimetic Compound Distinct from Caffeine. I: Purification and Chromatographic Analysis. Journal of Pharmaceutical Sciences, 80, 665-669. http://dx.doi.org/10.1002/jps.2600800711

[21] Tse, S.Y. (1992) Cholinomimetic Compound Distinct from Caffeine Contained in Coffee. II: Muscarinic Actions. Journal of Pharmaceutical Sciences, 81, 449-452. http://dx.doi.org/10.1002/jps.2600810512

[22] Kucherenko, Y.V., Wagner-Britz, L., Bernhardt, I. and Lang, F. (2013) Effect of Chloride Channel Inhibitors on Cytosolic $\mathrm{Ca}^{2+}$ Levels and $\mathrm{Ca}^{2+}$-Activated $\mathrm{K}^{+}$(Gardos) Channel Activity in Human Red Blood Cells. Journal of Membrane Biology, 246, 315-326. http://dx.doi.org/10.1007/s00232-013-9532-0

[23] van Eijk, J., van Campen, J.P., van der Jagt, H., Beijnen, J.H. and Tulner, L.R. (2013) Prevalence of Xerostomia and Its Relationship with Underlying Diseases, Medication, and Nutrition: A Descriptive Observational Study. Journal of the American Geriatrics Society, 61, 1836-1837. 
Scientific Research Publishing (SCIRP) is one of the largest Open Access journal publishers. It is currently publishing more than 200 open access, online, peer-reviewed journals covering a wide range of academic disciplines. SCIRP serves the worldwide academic communities and contributes to the progress and application of science with its publication.

Other selected journals from SCIRP are listed as below. Submit your manuscript to us via either submit@scirp.org or Online Submission Portal.
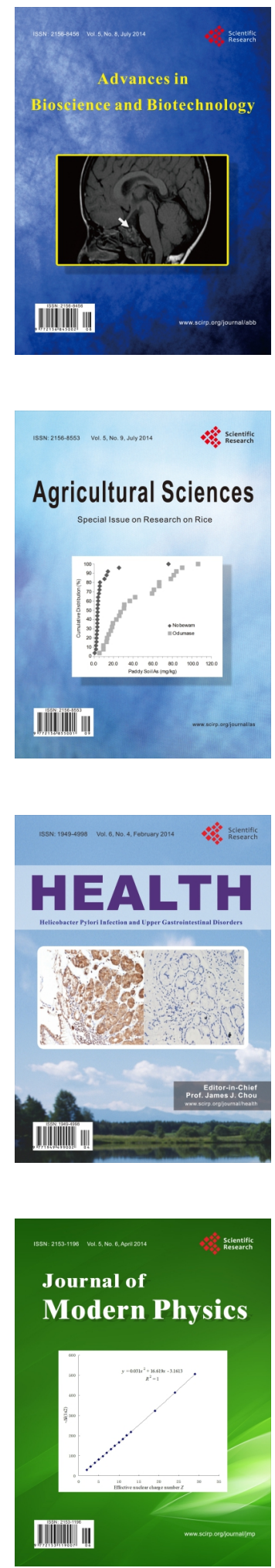
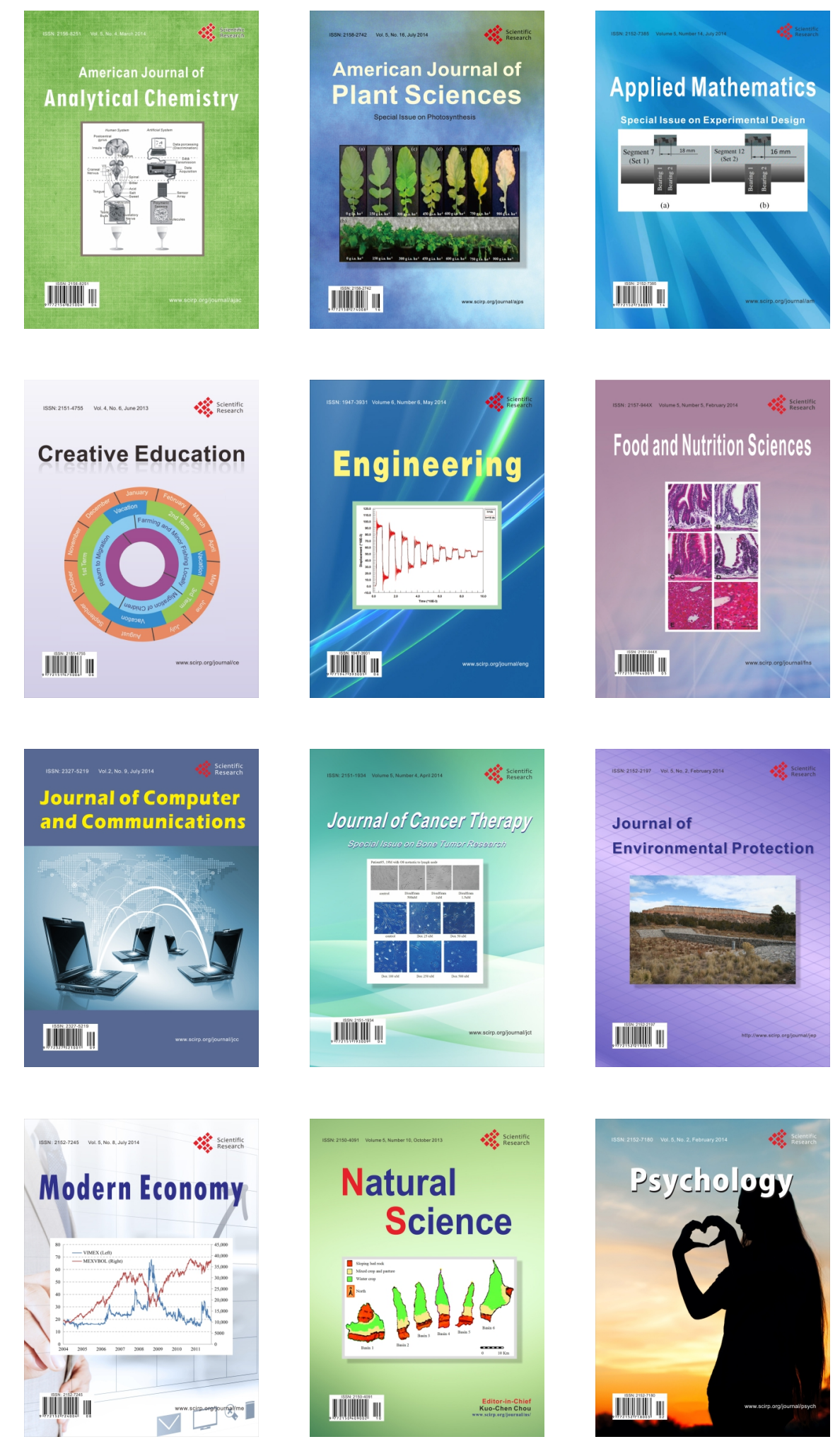